\title{
MECKEL'S DIVERTICULUM AS A CONDUIT IN ABDOMINAL MESOTHELIAL NODULAR HYPERPLASIA DUE TO CASTOMACH: A CASE REPORT
}

\author{
D. Srinivasan ${ }^{1}$, Sree Ramulu P. N², Sangmesh ${ }^{3}$, Harish Kumar', Prasanth K. Dhannur ${ }^{5}$
}

\section{HOW TO CITE THIS ARTICLE:}

D. Srinivasan, Sree Ramulu P. N, Sangmesh, Harish Kumar, Prasanth K. Dhannur. "Meckel's Diverticulum as a Conduit in Abdominal Mesothelial Nodular Hyperplasia due to Castomach: A Case Report". Journal of Evolution of Medical and Dental Sciences 2014; Vol. 3, Issue 41, September 04; Page: 10363-10366,

DOI: $10.14260 /$ jemds/2014/3345

ABSTRACT: A 23-year-old male patient presented to Surgical department for acute intestinal obstruction of 3 days duration, emergency laparotomy revealed $500-600 \mathrm{ml}$ of ascetic fluid, most of the small and whole of the large bowel omentum and anterior wall of the stomach was studded with numerous tubercles, the mesentery was tethered to the posterior abdominal wall due to extensive fibroses and the ileo-caecal junction was also fibrosed. During surgery we encountered technical difficulty of mobilizing any part of bowel for diversion, it so happened that a patient was blessed to have Meckel's diverticulum and diversion was performed similar to loop illeostomy. Histopathology of the omentum revealed nodular mesothelial hyperplasia, Oesopho-gastroduodenoscopy revealed antral growth of the stomach. Whole of case scenario been depicted.

KEYWORDS: Intestinal obstruction, Meckel's diverticulum diversion, Ca Stomach.

CASE DESCRIPTION: A male patient aged 23 years presented to emergency Surgery dept. with features suggestive of acute intestinal obstruction, scan and erect X ray-abdomen revealed intestinal obstruction of small bowel nature. Emergency laparotomy revealed - 500-600ml of ascetic fluid, most of small, large bowel, omentum, anterior wall of the stomach was studded with numerous tubercles, the mesentry was tethered to the posterior abdominal wall and the ileo caecal junction were also fibrosed.

During surgery it appeared to be impossible to mobilize part of the preterminal ileum out of the abdomen to do loop ileostomy diversion, but he had blessed with Meckel's Diverticulum which was 80 centimeters from the ileo caecal valve, the diverticulum was about $4 \mathrm{~cm}$ long, and the tip was free and was brought out of the abdomen and diversion done Fig: 1, 2, 3, 4.

Fig. 1: shows multiple tubercles in the mysentry and tethered to the posterior abdominal wall.

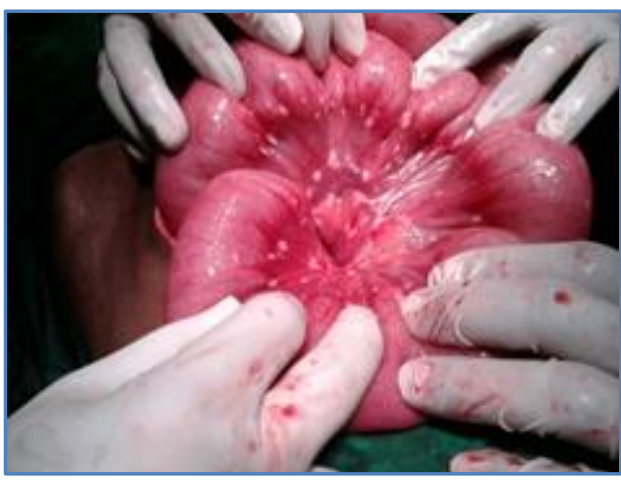

Fig. 1 


\section{CASE REPORT}

Fig. 2: the ileo-ceacal valve was also fibrosed with tubercles. Distal part of the ilium also shows bluish discoloration.

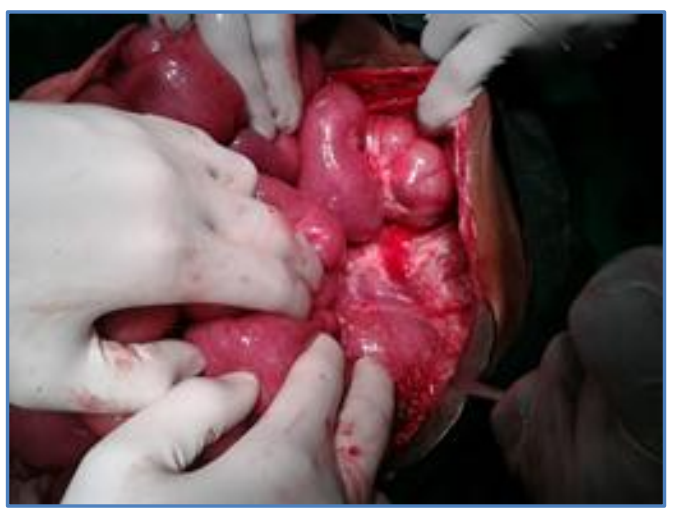

Fig. 2

Fig. 3: So much of fibroses that terminal ileum could not be mobilized for diversion.

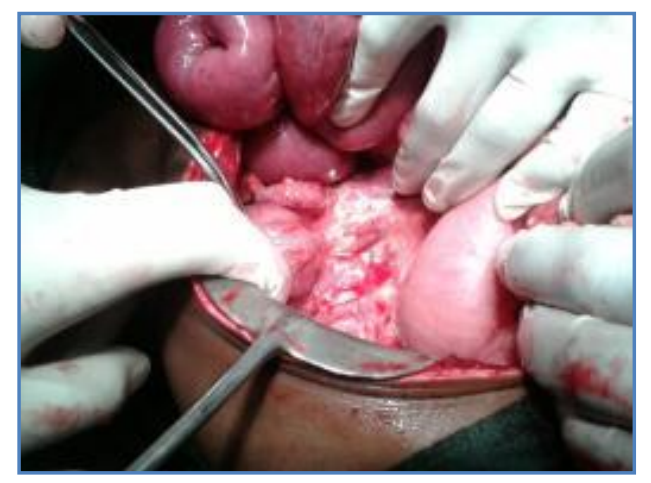

\section{Fig. 3}

Fig. 4: Patient was blessed with Meckel's diverticulum .mobilized and used as stoma for diversion of the intestinal content.

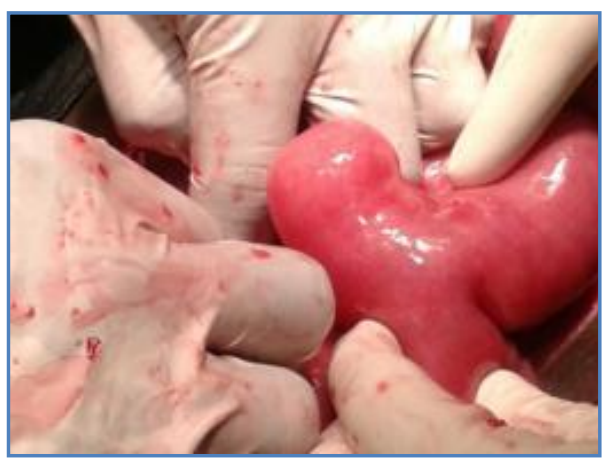

Fig. 4 
Fig. 5: the diversion created via the Meckel's diverticulum started functioning after 3days without any complications.

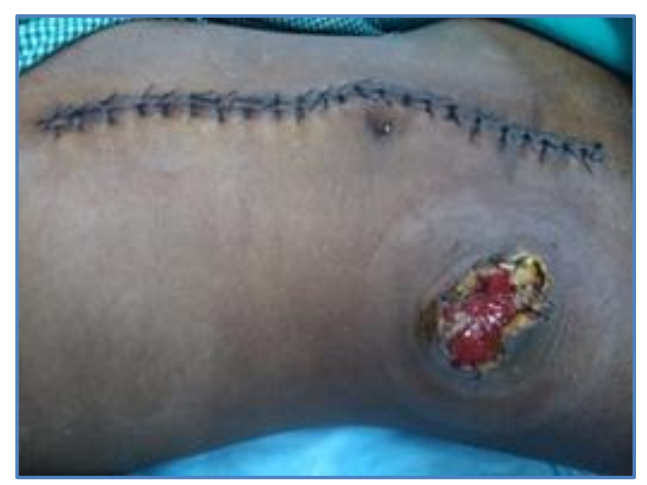

Fig. 5

Omentum of $2 \mathrm{x} .2 \mathrm{cms}$ biopsy was taken for histopathology. The histopathology report revealed nodular mesothelial hyperplasia .Colonoscopy was normal, hence the patient was subjected Oesophago Gastro Duodenoscopy to look for primary growth which revealed antral growth arising from the antral the stomach and Histopathological examination revealed C.A. stomach. The Meckel's diversion was functioning to its optimum.

DISCUSSION: To our knowledge, this is the first report on the use of a Meckel's diverticulum in the creation of stoma for diversion of intestinal contents for intestinal obstruction, when rest of the ileum and mysentry was studded with multiple tubercles tethered to the posterior abdomen.

There is a report, however, about the use of a Meckel's diverticulum to implant ureters to a Bricker derivation.[1] Also in non-oncological urologic surgery, The Meckel's diverticulum has been used for ureteric repair[2] and as an alternative conduit for the Mitrofanoff procedure. ${ }^{[3]}$ These are all case reports, except for Adams et al.[2] where the authors describe four cases.

\section{REFERENCES:}

1. Wyczólkowski M, Klima W, Kotuła J, Malik L. Meckel's diverticulum as the site of implanting ureter to the Bricker segment after radical cystectomy. The Journal of Urology. 2003; 169 (1):p. 285. [PubMed].

2. Adams J, Djakovic N, Gilfrich C, et al. Ureteric replacement with Meckel's diverticulum. BJU International. 2007; 99 (3): 647-650. [PubMed].

3. Prabhakaran K, Patankar JZ, Mali V. Meckel's diverticulum: an alternative conduit for the Mitrofanoff procedure. Journal of Postgraduate Medicine. 2003; 49 (2): 151-153. [PubMed]. 


\section{CASE REPORT}

\section{AUTHORS:}

1. D. Srinivasan

2. Sree Ramulu P. N.

3. Sangmesh

4. Harish Kumar

5. Prasanth K. Dhannur

\section{PARTICULARS OF CONTRIBUTORS:}

1. Assistant Professor, Department of Surgery, Sree Devaraj Urs Academy of Higher Education Research, Kolar, Karnataka.

2. Professor, Department of Surgery, Sree Devaraj Urs Academy of Higher Education Research, Kolar, Karnataka.

3. Assistant Professor, Department of Surgery, Sree Devaraj Urs Academy of Higher Education Research, Kolar, Karnataka.

4. Junior Resident, Department of Surgery, Sree Devaraj Urs Academy of Higher Education Research, Kolar, Karnataka.
5. Junior Resident, Department of Surgery, Sree Devaraj Urs Academy of Higher Education Research, Kolar, Karnataka.

\section{NAME ADDRESS EMAIL ID OF THE CORRESPONDING AUTHOR:}

Dr. Srinivasan,

Assistant Professor,

SDUAHER, Kolar-563101,

Karnataka.

Email: drsrinivasandorai@gmail.com

Date of Submission: 20/08/2014.

Date of Peer Review: 21/08/2014.

Date of Acceptance: 30/08/2014.

Date of Publishing: 04/09/2014. 